\title{
What factors impact the clinical outcome of magnetic resonance imaging-guided focused ultrasound thalamotomy for essential tremor?
}

\author{
Kenji Fukutome, MD, ${ }^{1}$ Yoshihiro Kuga, MD, PhD, ${ }^{1}$ Hideyuki Ohnishi, MD, PhD, ${ }^{1}$ \\ Hidehiro Hirabayashi, MD, PhD, ${ }^{1,2}$ and Hiroyuki Nakase, MD, PhD ${ }^{3}$
} 1Department of Neurosurgery, Ohnishi Neurological Center, Akashi, Hyogo; '2Department of Neurosurgery, National Hospital
Organization Nara Medical Center, Nara; ${ }^{3}$ Department of Neurosurgery, Nara Medical University, Kashihara, Nara, Japan

\begin{abstract}
OBJECTIVE Magnetic resonance imaging-guided focused ultrasound (MRgFUS) is a novel and useful treatment for essential tremor (ET); however, the factors impacting treatment outcome are unknown. The authors conducted this study to determine the factors affecting the outcome of MRgFUS.

METHODS From May 2016 through August 2017, 15 patients with ET were admitted to Ohnishi Neurological Center and treated with MRgFUS. To determine the factors impacting treatment outcome, the authors retrospectively studied correlations between the Clinical Rating Scale for Tremor (CRST) improvement rate and age, disease duration, baseline CRST score, skull density ratio (SDR), skull volume, maximum delivered energy, or maximum temperature.

RESULTS The mean CRST score was $18.5 \pm 5.8$ at baseline and $4.6 \pm 5.7$ at 1 year. The rate of improvement in the CRST score was $80 \% \pm 22 \%$. Younger age and lower baseline CRST score were correlated with a higher CRST improvement rate ( $p=0.025$ and 0.007 , respectively). To obtain a CRST improvement rate $\geq 50 \%$, a maximum temperature $\geq 55^{\circ} \mathrm{C}$ was necessary. There was no correlation between SDR and CRST improvement rate $(p=0.658)$. A lower SDR and higher skull volume required significantly higher maximum delivered energy ( $p=0.014$ and 0.016 , respectively). A higher maximum temperature was associated with a significantly larger lesion volume $(p=0.026)$.
\end{abstract}

CONCLUSIONS Younger age and lower baseline CRST score were favorable outcome factors. It is important to assess predictive factors when applying MRgFUS.

https://thejns.org/doi/abs/10.3171/2020.2.JNS192814

KEYWORDS focused ultrasound; thalamotomy; essential tremor; clinical rating scale for tremor; magnetic resonance imaging guided; ventral intermediate nucleus; skull density ratio; temperature; functional neurosurgery

$\mathrm{E}$ SSENTIAL tremor (ET) is the most common movement disorder in adults, with an estimated prevalence of $0.5 \%-5 \%{ }^{1,2}$ Although ET is not a lifethreatening condition, it can profoundly impact the quality of life of patients with severe symptoms. ${ }^{3,4}$ Patients report difficulty with everyday tasks such as eating, drinking, handwriting, and dressing. Many patients also experience social embarrassment regarding their tremor. Some will refrain from dining in public, and others will retire from employment early because of disabling symptoms. Medical therapy, particularly beta-blockers and primidone, is the first-line treatment for ET; however, medication alone is often insufficient to control severe symptoms and can have undesirable side effects. If resistance to medications develops or side effects are unacceptable, neurosurgical intervention is considered, primarily targeting the nucleus ventralis intermedius of the thalamus (Vim), a component of tremor circuitry that connects the cerebellum with cortical motor pathways. Conventionally, either deep brain stimulation or radiofrequency (RF) thalamotomy has been performed for patients with ET. These two surgical therapies effectively suppress tremor, ${ }^{5-25}$ but relatively few patients choose surgery because of the perceived invasiveness of the burr holes and intracerebral electrodes.

Magnetic resonance imaging-guided focused ultrasound (MRgFUS) has recently been developed as a treatment for brain diseases. Its effectiveness for the treatment of ET was first reported in a 2016 randomized controlled

ABBREVIATIONS CRST = Clinical Rating Scale for Tremor; ET = essential tremor; MRgFUS = magnetic resonance imaging-guided focused ultrasound; SDR = skull density ratio; Vim = nucleus ventralis intermedius of the thalamus.

SUBMITTED October 22, 2019. ACCEPTED February 25, 2020.

INCLUDE WHEN CITING Published online May 1, 2020; DOI: 10.3171/2020.2.JNS192814. 
trial. ${ }^{26}$ Thereafter, Park et al. and Sinai et al. reported sustained clinical efficacy 4 years after treatment. ${ }^{27,28} \mathrm{In}-$ vestigators have reported $40 \%-78 \%$ rates of hand tremor reduction at 1 year after MRgFUS. ${ }^{26,27,29,30}$ In previous studies, the rate of improvement among patients showing improvement has varied. There have been no detailed reports on the relation between patient or treatment factors and clinical outcome. Here, we report the factors impacting the clinical outcome of MRgFUS for ET.

\section{Methods \\ Patients}

This study was approved by the institutional review board of Ohnishi Neurological Center and adhered to the principles of the US Code of Federal Regulations, Title 45, Part 46, Protection of Human Subjects, Revised January 15, 2009, and the World Medical Association Declaration of Helsinki. Written consent was obtained from the patients at the time of treatment.

From May 2016 through August 2017, 15 consecutive patients with clinically significant refractory ET were admitted to Ohnishi Neurological Center. We referred to the study eligibility criteria of Elias et al. ${ }^{31}$ "Clinically significant" tremor in the dominant hand was defined as a score $>2$ on the postural or action item on the Clinical Rating Scale for Tremor (CRST), ranging from 0 to 4 (higher scores indicating worse tremor). "Refractory" tremor was defined as persistent disabling tremor despite more than 6 months of medical treatment. In all patients, the dominant hand was the more severely affected extremity and was targeted for treatment. The exclusion criteria were previous stereotactic or cranial surgery, other neurodegenerative condition, unstable cardiac conditions, substance abuse, current or past psychiatric disease, and a skull density ratio (SDR; ratio of cortical to cancellous bone) $<0.30$.

\section{Surgical Procedure}

The MRgFUS procedure was performed in a $1.5-\mathrm{T}$ MRI unit (Signa HDxt with a 16-channel head/neck/spine [HNS] coil, GE Healthcare Japan) using the ExAblate Neuro 4000 system (Insightec), which includes a hemispheric, $650-\mathrm{kHz}, 1024-\mathrm{element}$ phased-array transducer. In addition, CT scanning (Optima CT660 Pro 0.625-mm helical scan, GE Healthcare Japan) was performed on the day before treatment to measure the SDR and detect calcified structures. Daily quality assurance was performed as a calibration using the phantom on both the day before and the day of treatment.

Before the procedure, the patient's head hair was completely shaved to prevent irregular reflection of ultrasound, followed by attachment of the stereotactic frame to the patient's head under local anesthesia. At this time, the frame was symmetrically attached, with the front pins placed just above the eyebrows and the rear pins placed on the superior nuchal line to obtain the maximum skull area. After attaching a rubber membrane, the patient was transferred to the MRI couch and connected to an ultrasonic transducer. After circulating chilled, degassed water between the head and the transducer, we determined the target with
T2-weighted MRI and planned treatment by fusing an MR image with a preoperative CT image. Typically, the target was the contralateral Vim, which was $10.5-11 \mathrm{~mm}$ lateral from the third ventricle wall and $5-5.5 \mathrm{~mm}$ behind the midpoint of the intercommissural line at the level of the midcommissural point. After treatment planning, a series of low-power sonications confirmed accurate focusing in three orthogonal planes by means of MR thermography. We also ascertained any adverse effects on the patient between sonications while gradually escalating the energy. When the temperature of the target had risen to $\geq 55^{\circ} \mathrm{C}$, which was the therapeutic temperature, the treatment was completed when improvement of the tremor was determined according to the patient's manual drawing and writing performance, after which the frame was removed. In cases of inadequate improvement of symptoms, the focus of acoustic energy was moved posteriorly or inferiorly within a range of $1 \mathrm{~mm}$ in each coordinate. MR images were obtained immediately after treatment and 1 day, 1 month, and 1 year after treatment. The volume of the lesion was determined based on the markedly hyperintense lesion that is the cytotoxic edema region described as zone 2 (including zone 1) by Wintermark et al. on 2-mm slice T2-weighted images. ${ }^{32}$ The spheroid volume formula $4 / 3$ $\times \pi \times(\mathrm{x} / 2) \times(\mathrm{y} / 2) \times(\mathrm{z} / 2)$ was used to calculate lesion volume.

\section{Assessment of Effectiveness}

We retrospectively evaluated the CRST improvement rate of the 15 patients with medically refractory ET who had been treated with MRgFUS and followed up for 1 year. The CRST improvement rate was calculated using the following equation: [(baseline CRST score - 1-year CRST score)/baseline CRST score] $\times 100$. Here, "CRST score" refers to the tremor score in the affected hand. The total score was calculated by adding the scores for CRST part A in the affected hand (resting, postural, and action tremor; 0-4 for each item) and the scores for CRST part B in the affected hand (drawing of two Archimedes' spirals and straight lines, handwriting, and pouring water; 0-4 for each item). ${ }^{27}$ The affected hand scores ranged from 0 to 32 , with a higher score indicating a more severe tremor. We evaluated correlations between the CRST improvement rate and various factors and between the factors.

\section{Statistical Analysis}

Statistical analyses were performed using ystat 2018 (IgakuTosho Shuppan). Spearman's correlation test was used to analyze the correlations. The F-test was used to analyze the scattering of correlations between SDR and delivered sonication energy. We considered a $p<0.05$ to indicate statistical significance.

\section{Results}

\section{Patient Characteristics and Treatment Factors}

The 15 patients consisted of 4 women and 11 men, including one left-handed man (Table 1). The mean age was $62.9 \pm 11.3$ years (mean \pm standard deviation), with a range from 41 to 82 years. The mean disease duration was 21.5 \pm 14.0 years, with a range from 2 to 47 years. The mean 
TABLE 1. Summary of patient characteristics and treatment factors

\begin{tabular}{|c|c|c|c|c|c|c|c|c|c|c|c|c|}
\hline \multirow[b]{2}{*}{$\begin{array}{c}\text { Case } \\
\text { No. }\end{array}$} & \multirow[b]{2}{*}{$\begin{array}{l}\text { Age } \\
\text { (yrs) }\end{array}$} & \multirow[b]{2}{*}{ Sex } & \multirow{2}{*}{$\begin{array}{c}\text { Disease } \\
\text { Duration } \\
\text { (yrs) }\end{array}$} & \multirow{2}{*}{$\begin{array}{c}\text { Baseline } \\
\text { CRST } \\
\text { Score }\end{array}$} & \multirow[b]{2}{*}{ Tx Side } & \multirow[b]{2}{*}{ SDR } & \multirow[b]{2}{*}{$\begin{array}{c}\text { Skull Vol } \\
\left(\mathrm{cm}^{3}\right)\end{array}$} & \multirow{2}{*}{$\begin{array}{l}\text { No. of } \\
\text { Elements } \\
\text { Used }\end{array}$} & \multirow{2}{*}{$\begin{array}{l}\text { Max Delivered } \\
\text { Sonication } \\
\text { Energy (J) }\end{array}$} & \multirow{2}{*}{$\begin{array}{c}\text { Max } \\
\text { Temperature } \\
\left({ }^{\circ} \mathrm{C}\right)\end{array}$} & \multicolumn{2}{|c|}{ Lesion Vol $\left(\mathrm{mm}^{3}\right)$} \\
\hline & & & & & & & & & & & $\begin{array}{c}1 \text { Day } \\
\text { After Tx }\end{array}$ & $\begin{array}{c}1 \text { Yr After } \\
\text { Tx }\end{array}$ \\
\hline 1 & 64 & M & 43 & 15 & $\mathrm{Lt}$ & 0.42 & 216 & 948 & 16,937 & 57 & 113.3 & 10.4 \\
\hline 2 & 64 & $M$ & 8 & 15 & $\mathrm{Lt}$ & 0.42 & 226 & 956 & 12,471 & 56 & 72.2 & 0 \\
\hline 3 & 82 & $M$ & 36 & 24 & $\mathrm{Lt}$ & 0.43 & 239 & 961 & 17,792 & 56 & 64.0 & 0 \\
\hline 4 & 58 & $M$ & 5 & 25 & $\mathrm{Lt}$ & 0.44 & 307 & 972 & 13,709 & 60 & 83.5 & 0 \\
\hline 5 & 74 & $M$ & 27 & 23 & $\mathrm{Lt}$ & 0.48 & 201 & 953 & 14,552 & 58 & 55.8 & 8.6 \\
\hline 6 & 45 & $F$ & 10 & 15 & $\mathrm{Lt}$ & 0.39 & 247 & 984 & 14,646 & 56 & 34.4 & 11.6 \\
\hline 7 & 67 & $\mathrm{~F}$ & 2 & 28 & $\mathrm{Lt}$ & 0.30 & 232 & 927 & 33,018 & 54 & 19.7 & 12.6 \\
\hline 8 & 57 & $\mathrm{~F}$ & 36 & 11 & $\mathrm{Lt}$ & 0.49 & 224 & 920 & 8,019 & 55 & 43.0 & 7.1 \\
\hline 9 & 53 & $F$ & 47 & 14 & $\mathrm{Lt}$ & 0.39 & 269 & 966 & 32,211 & 56 & 68.5 & 9.9 \\
\hline 10 & 65 & M & 16 & 15 & $\mathrm{Lt}$ & 0.36 & 171 & 912 & 10,098 & 58 & 78.2 & 6.1 \\
\hline 11 & 59 & M & 21 & 15 & $\mathrm{Lt}$ & 0.35 & 193 & 923 & 10,803 & 59 & 55.6 & 7.4 \\
\hline 12 & 67 & M & 10 & 16 & $\mathrm{Lt}$ & 0.46 & 249 & 894 & 17,236 & 56 & 54.1 & 13.6 \\
\hline 13 & 41 & $\mathrm{M}$ & 21 & 12 & $\mathrm{Lt}$ & 0.41 & 202 & 917 & 28,694 & 58 & 77.8 & 0 \\
\hline 14 & 78 & M & 15 & 22 & $\mathrm{Lt}$ & 0.80 & 303 & 945 & 4,791 & 60 & 59.7 & 5.4 \\
\hline 15 & 70 & $M$ & 26 & 28 & $\mathrm{Rt}$ & 0.54 & 336 & 930 & 9,151 & 60 & 141.8 & 0 \\
\hline Mean & 62.9 & & 21.5 & 18.5 & & 0.45 & 219 & 941 & 16,275 & 57.3 & 68.0 & 6.2 \\
\hline
\end{tabular}

$\mathrm{Tx}=$ treatment.

baseline CRST score was $18.5 \pm 5.8$, with a range from 11 to 28 . The mean SDR was $0.45 \pm 0.11$, with a range from 0.30 to 0.80 . The mean skull volume was $219 \pm 42 \mathrm{~cm}^{3}$, with a range from 171 to $336 \mathrm{~cm}^{3}$. The mean maximum delivered sonication energy was $16,275 \pm 8610 \mathrm{~J}$, with a range from 4791 to $33,018 \mathrm{~J}$. The maximum mean temperature was $57.3^{\circ} \mathrm{C} \pm 1.9^{\circ} \mathrm{C}$, with a range from $54^{\circ} \mathrm{C}$ to $60^{\circ} \mathrm{C}$. The mean lesion volume at 1 day after treatment was $68.0 \pm 29.8 \mathrm{~mm}^{3}$, with a range from 19.7 to $141.8 \mathrm{~mm}^{3}$. The mean lesion volume at 1 year after treatment was 6.2 $\pm 5.0 \mathrm{~mm}^{3}$, with a range from 0 to $13.6 \mathrm{~mm}^{3}$. In 5 patients, we could not measure lesion volume at 1 year given the disappearance of the lesion (lesion volume $=0 \mathrm{~mm}^{3}$ ).

\section{Clinical Outcome and Adverse Events}

Clinical outcome was evaluated according to the change in CRST score. The mean CRST score at 1 year after operation was $4.6 \pm 5.7$, and the improvement rate was $80 \% \pm 22 \%$ (Fig. 1). Tremor was improved immediately after treatment, and the improvement was sustained for 1 year. In 8 of the 15 patients, tremor improved by over $90 \%$, and the effect persisted for 1 year. Tremor control was unsatisfactory in 1 patient. Nine patients reported headache, vomiting, or dizziness during treatment. One patient developed ataxia but improved 8 months later. One patient had a permanent adverse effect of numbness of the lips.

\section{Factors Affecting Clinical Outcome}

We investigated the factors affecting clinical outcome (Table 2). Only age and baseline CRST score significantly affected clinical outcome. Younger patients had a better outcome $\left(\mathrm{p}=0.025, \mathrm{r}^{2}=0.269, \mathrm{y}=144.406-1.024 \mathrm{x}\right)$.
Patients with lower baseline CRST scores also had better outcomes $\left(\mathrm{p}=0.007, \mathrm{r}^{2}=0.544, \mathrm{y}=132.413-2.829 x\right)$. In 1 patient, the maximum temperature remained at $54^{\circ} \mathrm{C}$ and the CRST improvement rate was only $35.7 \%$. All other patients attained a maximum temperature $\geq 55^{\circ} \mathrm{C}$ and had a CRST improvement rate $\geq 50 \%$. Lower maximum temperature was correlated with a higher CRST improvement rate except for the 1 patient with a maximum temperature of $54^{\circ} \mathrm{C}\left(\mathrm{p}=0.023, \mathrm{r}^{2}=0.353, \mathrm{y}=461.121-6.574 \mathrm{x}\right)$. Disease duration, SDR, skull volume, number of elements used, and maximum delivered sonication energy were not correlated with the CRST improvement rate $(\mathrm{p}=0.429$, $0.657,0.227,0.566$, and 0.652 , respectively). Younger age was correlated with a lower baseline CRST score $(\mathrm{p}=$ $\left.0.003, r^{2}=0.380, y=0.317 x-1.438\right)$. Figure $2 A$ shows the

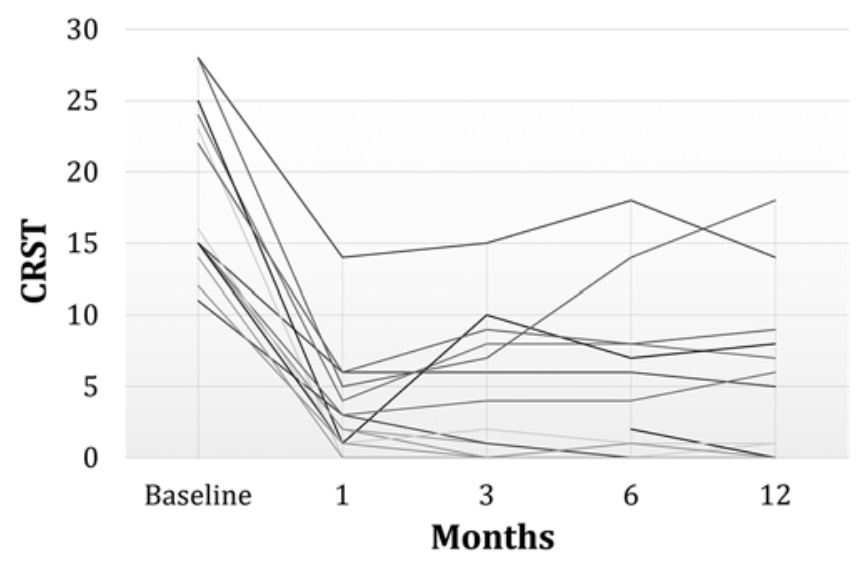

FIG. 1. Change in mean CRST score according to month. 
TABLE 2. Effect of different factors on clinical outcome

\begin{tabular}{lccc}
\hline \multicolumn{1}{c}{ Factor } & $\mathrm{p}$ Value & $\mathrm{r}^{2}$ & $\mathrm{y}$ \\
\hline Age & $\mathbf{0 . 0 2 5}$ & $\mathbf{0 . 2 6 9}$ & $\mathbf{1 4 4 . 4 0 6 - 1 . 0 2 4 \mathrm { x }}$ \\
\hline Disease duration & 0.429 & 0.048 & $72.472+0.349 \mathrm{x}$ \\
\hline Baseline CRST score & $\mathbf{0 . 0 0 7}$ & $\mathbf{0 . 5 4 4}$ & $\mathbf{1 3 2 . 4 1 3 - 2 . 8 2 9 \mathrm { x }}$ \\
\hline SDR & 0.657 & 0.022 & $92.687-28.532 \mathrm{x}$ \\
\hline Skull volume & 0.227 & 0.060 & $51.396+0.130 \mathrm{x}$ \\
\hline No. of elements used & 0.566 & 0.009 & $2.512+0.082 \mathrm{x}$ \\
\hline Max delivered energy & 0.652 & 0.000 & $79.760+0.000 \mathrm{x}$ \\
\hline Max temperature & 0.279 & 0.031 & $197.723-2.056 \mathrm{x}$ \\
\hline Max temperature $\geq 55^{\circ} \mathrm{C}$ & $\mathbf{0 . 0 2 3}$ & $\mathbf{0 . 3 5 3}$ & $\mathbf{4 6 1 . 1 2 1 - 6 . 5 7 4 x}$ \\
\hline
\end{tabular}

Boldface type indicates statistically significant results.

relation between SDR and the delivered energy of all sonications that reached $\geq 55^{\circ} \mathrm{C}$ in all the treatments. SDR was negatively correlated with the delivered energy $(\mathrm{p}=0.014$, $\mathrm{r}^{2}=0.3857, \mathrm{y}=37975 \mathrm{e}^{-2.615 x}$. Additionally, in patients with an SDR $<0.45$, the delivered energy was significantly more scattered than in patients with an SDR $\geq 0.45$ ( $\mathrm{p}=$ 0.015 ). Furthermore, skull volume was positively correlated with maximum delivered energy $\left(\mathrm{p}=0.016, \mathrm{r}^{2}=0.372\right.$, $\mathrm{y}=2.1893 \mathrm{x}^{1.6352}$; Fig. 2B). Maximum mean temperature was positively correlated with lesion volume $\left(\mathrm{p}=0.026, \mathrm{r}^{2}\right.$ $=0.037, \mathrm{y}=-471.72+9.41 \mathrm{x})$; however, cases with a higher maximum temperature did not have more complications.
The SDR, maximum delivered energy, skull volume, number of elements, and maximum mean temperature were not correlated with the CRST improvement rate.

\section{Discussion}

Federau et al. showed that the volume of tissue in which the thermal dose reached at least a 240-minute dose $\left(\operatorname{dose}_{240}\right)$, which is the generally accepted threshold above which total necrosis is observed, lesion volume immediately posttreatment and 1 year later was correlated with clinical outcome. ${ }^{29}$ They concluded that a dose ${ }_{240}$ that will result in a total lesion volume of $36 \mathrm{~mm}^{3}$ and a lesion of $11 \mathrm{~mm}^{3}$ in the Vim after 1 year is necessary to maintain an improvement of more than 15 points in the CRST hand score after 1 year. In contrast, Tsolaki et al. reported that there was no correlation between lesion volume and CRST improvement rate at 1 month and 1 year. ${ }^{33}$ Hariz and Hirabayashi also reported that there was no correlation between lesion volume and clinical outcome in cases of RF thalamotomy. ${ }^{34}$ Five patients in our study showed remarkable effects (CRST improvement rates of 50\%-100\%) even though there was no obvious coagulation lesion after 1 year. Therefore, we considered that a large lesion volume was not always required to achieve a sufficient clinical effect. Moreover, Boutet et al. showed that lesions larger than $170 \mathrm{~mm}^{3}$ were associated with an increased risk of acute adverse effects. ${ }^{35}$ From the above considerations, we believe that it is important that a lesion be formed at the optimal site even if the lesion volume is

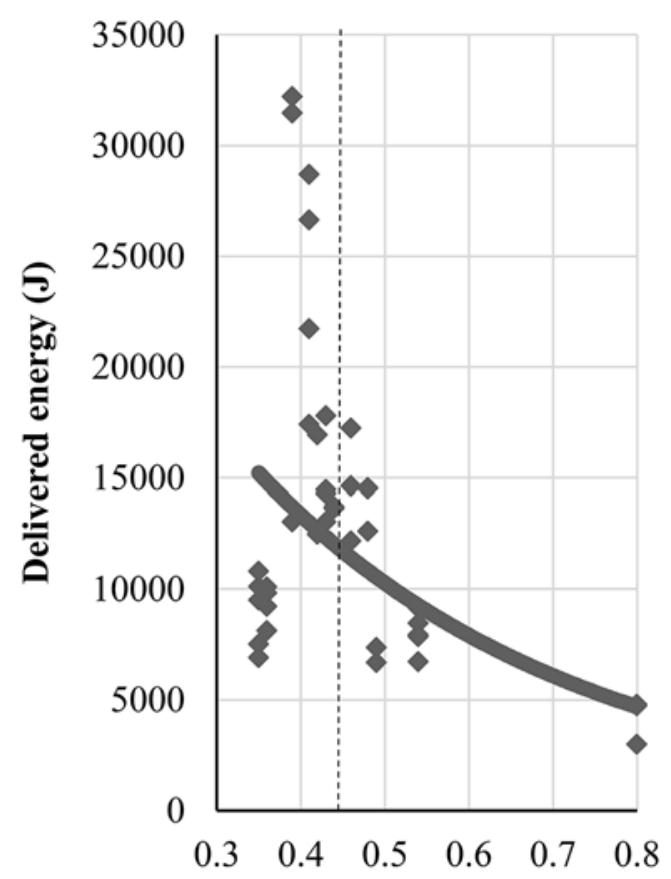

A

SDR

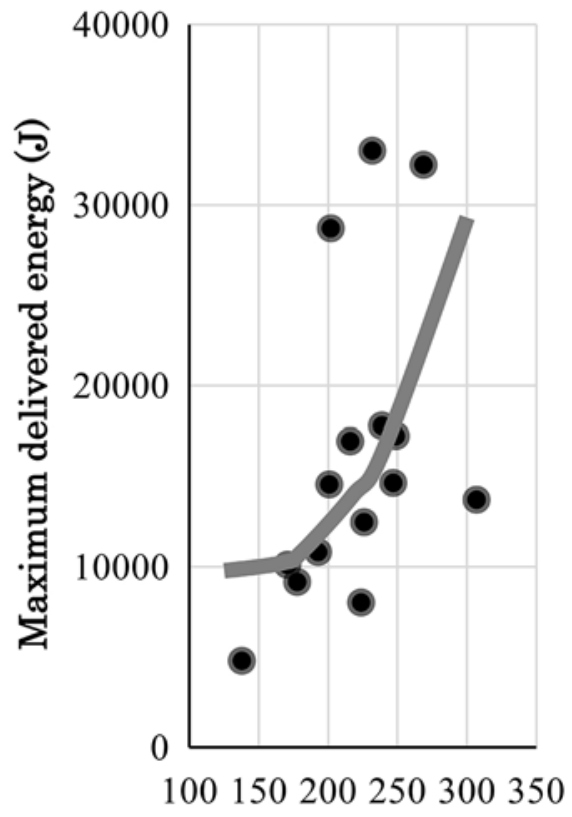

B

Skull volume $\left(\mathrm{cm}^{3}\right)$

FIG. 2. A: Relation between SDR and the delivered energy of all sonications that reached $\geq 55^{\circ} \mathrm{C}$ in all the treatments. SDR was negatively correlated with the delivered energy $\left(p=0.014, r^{2}=0.3857, y=37975 e^{-2.615 x}\right)$. In cases with an SDR $<0.45$, the required delivered energy was significantly more scattered than in the cases with an SDR $\geq 0.45(p=0.015)$. B: There was a positive correlation between skull volume and maximum delivered energy $\left(p=0.016, r^{2}=0.372, y=2.1893 x^{1.6352}\right)$. 
small and that an unnecessarily large lesion only increases adverse effects.

It is well known that the degree of temperature increase is crucial for successful treatment during thermal lesioning. For example, 1 second at $57^{\circ} \mathrm{C}$ and 3.5 seconds at $55^{\circ} \mathrm{C}$ are known to be sufficient for tissue necrosis, whereas a maximum temperature of $54^{\circ} \mathrm{C}$ requires 7 seconds for tissue necrosis. ${ }^{36,37}$ In our study, the target temperature was $\geq 55^{\circ} \mathrm{C}$, but the duration of maximum temperature did not matter. All patients who could attain a maximum temperature $\geq 55^{\circ} \mathrm{C}$ had a CRST improvement rate $\geq 50 \%$. The reason that there was a correlation between lower maximum temperature and higher CRST improvement rate is unknown. However, it is assumed that $55^{\circ} \mathrm{C}$ is a high enough temperature for successful treatment.

Krishna et al. evaluated factors that correlated with clinical outcome from another point of view. They concluded that tractography-guided targeting was safe and that the short-term outcome was good (mean CRST improvement rate at 3 months: $55.7 \%$ ). ${ }^{38}$ This outcome is not better than the outcome of our study; however, their method should be taken into consideration for safer treatment.

Sinai et al. reported that sex, age, disease duration, and tremor scores did not correlate with clinical outcome.28 On the other hand, younger age and lower baseline CRST score were correlated with a higher CRST improvement rate in our study. It is easy to predict that a lower baseline CRST score is likely to improve, and since younger patients had lower baseline CRST scores, younger patients had a higher CRST improvement rate as well. Given the abovementioned results, it is advisable to administer early treatment if a patient has some difficulties in activities of daily life and the patient wants to undergo treatment. Chang et al. reported that skull volume and SDR were positively and negatively correlated, respectively, with maximum mean temperature. ${ }^{36}$ They also reported that an SDR $>0.45$ may predict a lower energy requirement, and an SDR $\geq 0.45$ was one of the inclusion criteria in a previous randomized controlled study. ${ }^{26,36}$ An SDR $\geq 0.45$ may be reasonable for stable treatment. Boutet et al. reported that a lower SDR was correlated with higher maximum delivered energy but not with clinical outcome. ${ }^{39}$ Therefore, they considered that a lower SDR was not a nonconformity factor for MRgFUS. In our study, skull volume and SDR were not correlated with maximum mean temperature. Skull volume and SDR were positively and negatively correlated, respectively, with mean maximum delivered energy, in agreement with Chang's results. The amount of required energy varies if SDR is $<0.45$, and it is difficult to predict the temperature rise. However, regardless of the SDR values and skull volume, if there is the required energy, the target maximum mean temperature will be achieved; thus, SDR and skull volume are not considered to be correlated with maximum mean temperature. Actually, many patients in our study whose SDR was $<0.4$ underwent MRgFUS and had a successful outcome. However, if the SDR is $<0.4$, the temperature rise is not stable; therefore, it was considered difficult to predict the effect of MRgFUS.

Our study has some limitations. First, it was a retrospective study. Second, changes in the target during treat- ment were not considered, which may have affected lesion volume and clinical outcome. Finally, it is possible that the CRST improvement rate after 1 year did not reflect the true effect of MRgFUS. Because some recurrence may happen 1 year after treatment, outcomes at 1 or 3 months may be more appropriate for evaluating the outcome.

\section{Conclusions}

Younger age and lower baseline CRST score were correlated with a better outcome. SDR was not always correlated with the CRST improvement rate. Evaluation of patient factors before treatment is beneficial for the selection of patients.

\section{Acknowledgments}

We would like to thank Enago for the English language review.

\section{References}

1. Findley LJ. Epidemiology and genetics of essential tremor. Neurology. 2000;54(11)(suppl 4):S8-S13.

2. Louis ED, Ferreira JJ. How common is the most common adult movement disorder? Update on the worldwide prevalence of essential tremor. Mov Disord. 2010;25(5):534-541.

3. Lorenz D, Schwieger D, Moises H, Deuschl G. Quality of life and personality in essential tremor patients. Mov Disord. 2006;21(8):1114-1118.

4. Tröster AI, Pahwa R, Fields JA, et al. Quality of life in Essential Tremor Questionnaire (QUEST): development and initial validation. Parkinsonism Relat Disord. 2005;11(6):367-373.

5. Akbostanci MC, Slavin KV, Burchiel KJ. Stereotactic ventral intermedial thalamotomy for the treatment of essential tremor: results of a series of 37 patients. Stereotact Funct Neurosurg. 1999;72(2-4):174-177.

6. Baizabal-Carvallo JF, Kagnoff MN, Jimenez-Shahed J, et al. The safety and efficacy of thalamic deep brain stimulation in essential tremor: 10 years and beyond. J Neurol Neurosurg Psychiatry. 2014;85(5):567-572.

7. Blomstedt P, Hariz GM, Hariz MI, Koskinen LO. Thalamic deep brain stimulation in the treatment of essential tremor: a long-term follow-up. Br J Neurosurg. 2007;21(5):504-509.

8. Cury RG, Fraix V, Castrioto A, et al. Thalamic deep brain stimulation for tremor in Parkinson disease, essential tremor, and dystonia. Neurology. 2017;89(13):1416-1423.

9. Dallapiazza RF, Lee DJ, De Vloo P, et al. Outcomes from stereotactic surgery for essential tremor. J Neurol Neurosurg Psychiatry. 2019;90(4):474-482.

10. Goldman MS, Ahlskog JE, Kelly PJ. The symptomatic and functional outcome of stereotactic thalamotomy for medically intractable essential tremor. J Neurosurg. 1992;76(6):924928.

11. Graff-Radford J, Foote KD, Mikos AE, et al. Mood and motor effects of thalamic deep brain stimulation surgery for essential tremor. Eur J Neurol. 2010;17(8):1040-1046.

12. Huss DS, Dallapiazza RF, Shah BB, et al. Functional assessment and quality of life in essential tremor with bilateral or unilateral DBS and focused ultrasound thalamotomy. Mov Disord. 2015;30(14):1937-1943.

13. Jankovic J, Cardoso F, Grossman RG, Hamilton WJ. Outcome after stereotactic thalamotomy for parkinsonian, essential, and other types of tremor. Neurosurgery. 1995;37(4):680-687.

14. Lyons KE, Pahwa R, Busenbark KL, et al. Improvements in 
daily functioning after deep brain stimulation of the thalamus for intractable tremor. Mov Disord. 1998;13(4):690-692.

15. Mohadjer M, Goerke H, Milios E, et al. Long-term results of stereotaxy in the treatment of essential tremor. Stereotact Funct Neurosurg. 1990;54-55:125-129.

16. Nagaseki Y, Shibazaki T, Hirai T, et al. Long-term followup results of selective VIM-thalamotomy. J Neurosurg. 1986;65(3):296-302.

17. Nazzaro JM, Pahwa R, Lyons KE. Long-term benefits in quality of life after unilateral thalamic deep brain stimulation for essential tremor. J Neurosurg. 2012;117(1):156-161.

18. Niranjan A, Jawahar A, Kondziolka D, Lunsford LD. A comparison of surgical approaches for the management of tremor: radiofrequency thalamotomy, gamma knife thalamotomy and thalamic stimulation. Stereotact Funct Neurosurg. 1999;72(24):178-184.

19. Obwegeser AA, Uitti RJ, Turk MF, et al. Thalamic stimulation for the treatment of midline tremors in essential tremor patients. Neurology. 2000;54(12):2342-2344.

20. Pahwa R, Lyons KE, Wilkinson SB, et al. Long-term evaluation of deep brain stimulation of the thalamus. J Neurosurg. 2006;104(4):506-512.

21. Pilitsis JG, Metman LV, Toleikis JR, et al. Factors involved in long-term efficacy of deep brain stimulation of the thalamus for essential tremor. J Neurosurg. 2008;109(4):640-646.

22. Shahzadi S, Tasker RR, Lozano A. Thalamotomy for essential and cerebellar tremor. Stereotact Funct Neurosurg. 1995;65(1-4):11-17.

23. Sobstyl M, Zabek M, Koziara H, et al. Stereotactic ventrolateral thalamotomy in the treatment of essential tremor. Article in Polish. Neurol Neurochir Pol. 2006;40(3):179-185.

24. Tasker RR. Deep brain stimulation is preferable to thalamotomy for tremor suppression. Surg Neurol. 1998;49(2):145154.

25. Zirh A, Reich SG, Dougherty PM, Lenz FA. Stereotactic thalamotomy in the treatment of essential tremor of the upper extremity: reassessment including a blinded measure of outcome. J Neurol Neurosurg Psychiatry. 1999;66(6):772-775.

26. Elias WJ, Lipsman N, Ondo WG, et al. A randomized trial of focused ultrasound thalamotomy for essential tremor. $N$ Engl J Med. 2016;375(8):730-739.

27. Park YS, Jung NY, Na YC, Chang JW. Four-year followup results of magnetic resonance-guided focused ultrasound thalamotomy for essential tremor. Mov Disord. 2019;34(5):727-734.

28. Sinai A, Nassar M, Eran A, et al. Magnetic resonance-guided focused ultrasound thalamotomy for essential tremor: a 5-year single-center experience [published online July 5, 2019]. J Neurosurg. doi:10.3171/2019.3.JNS19466

29. Federau C, Goubran M, Rosenberg J, et al. Transcranial MRI-guided high-intensity focused ultrasound for treatment of essential tremor: A pilot study on the correlation between lesion size, lesion location, thermal dose, and clinical outcome. J Magn Reson Imaging. 2018;48(1):58-65.

30. Kim M, Jung NY, Park CK, et al. Comparative evaluation of magnetic resonance-guided focused ultrasound surgery for essential tremor. Stereotact Funct Neurosurg. 2017;95(4):279-286.
31. Elias WJ, Huss D, Voss T, et al. A pilot study of focused ultrasound thalamotomy for essential tremor. $N$ Engl J Med. 2013;369(7):640-648.

32. Wintermark M, Druzgal J, Huss DS, et al. Imaging findings in MR imaging-guided focused ultrasound treatment for patients with essential tremor. AJNR Am J Neuroradiol. 2014;35(5):891-896.

33. Tsolaki E, Downes A, Speier W, et al. The potential value of probabilistic tractography-based for MR-guided focused ultrasound thalamotomy for essential tremor. Neuroimage Clin. 2017;17:1019-1027.

34. Hariz MI, Hirabayashi H. Is there a relationship between size and site of the stereotactic lesion and symptomatic results of pallidotomy and thalamotomy? Stereotact Funct Neurosurg. 1997;69(1-4 Pt 2):28-45.

35. Boutet A, Ranjan M, Zhong J, et al. Focused ultrasound thalamotomy location determines clinical benefits in patients with essential tremor. Brain. 2018;141(12):3405-3414.

36. Chang WS, Jung HH, Zadicario E, et al. Factors associated with successful magnetic resonance-guided focused ultrasound treatment: efficiency of acoustic energy delivery through the skull. J Neurosurg. 2016;124(2):411-416.

37. Sapareto SA, Dewey WC. Thermal dose determination in cancer therapy. Int J Radiat Oncol Biol Phys. 1984;10(6):787-800.

38. Krishna V, Sammartino F, Agrawal P, et al. Prospective tractography-based targeting for improved safety of focused ultrasound thalamotomy. Neurosurgery. 2019;84(1):160-168.

39. Boutet A, Gwun D, Gramer R, et al. The relevance of skull density ratio in selecting candidates for transcranial MRguided focused ultrasound. J Neurosurg. 2020;132(6):17851791.

\section{Disclosures}

This study was partially supported by Insightec, which assisted only by calculating SDR.

\section{Author Contributions}

Conception and design: Fukutome. Acquisition of data: Fukutome, Kuga, Ohnishi. Analysis and interpretation of data: Fukutome. Drafting the article: Fukutome. Critically revising the article: Hirabayashi. Reviewed submitted version of manuscript: Kuga, Ohnishi, Hirabayashi. Statistical analysis: Fukutome. Administrative/technical/material support: Fukutome. Study supervision: Hirabayashi, Nakase.

\section{Correspondence}

Kenji Fukutome: Ohnishi Neurological Center, Akashi, Hyogo, Japan.kenjifukutome82@gmail.com. 